\title{
NILAI-NILAI PENDIDIKAN \\ DALAM KITAB WANA PARWA \\ SEBAGAI PEDOMAN BAGI SISWA HINDU
}

\author{
Made Mardika \\ SD Saraswati 6 Denpasar \\ mardikamade80@gmail.com
}

\begin{tabular}{|c|c|}
\hline \multicolumn{2}{|l|}{$\begin{array}{l}\text { Riwayat Jurnal } \\
\text { Artikel diterima: } \\
\text { Artikel direvisi: } \\
\text { Artikel disetujui: }\end{array}$} \\
\hline $\begin{array}{l}\text { Kata Kunci: } \\
\text { Wana Parwa } \\
\text { Mahabratta } \\
\text { Nilai Pendidikan Hindu }\end{array}$ & $\begin{array}{l}\text { Abstrak } \\
\text { Kitab Weda merupakan sumber ajaran pokok agama Hindu yang } \\
\text { dijadikan sebagai pedoman dan diaplikasikan dalam kehidupan } \\
\text { sehari-hari. Mahabratta termasuk dalam kitab Itihasa yang } \\
\text { merupakan sebuah awal dalam mempelajari kitab suci Weda. } \\
\text { Didalam Bagian-bagian Parwa Mahabratta terkandung nilai-nilai } \\
\text { pendidikan yang sangat luhur yang diajarkan dan dijadikan } \\
\text { pedoman bagi siswa Hindu. Kitab Wana Parwa merupakan salah } \\
\text { satu bagian dari kitab Mahabratta, didalam kitab Wana parwa } \\
\text { banyak terkandung nilai-nilai pendidikan yang dapat dijadikan } \\
\text { pedoman bagi siswa Hindu. Keberadaan kitab Wana Parwa } \\
\text { dikalangan masyarakat Hindu dapat dijadikan pedoman dalam } \\
\text { kehidupan sehari-hari, sedangkan nilai-nilai pendidikan yang } \\
\text { terkandung didalamnya dapat dijadikan pedoman dalam } \\
\text { kehidupan sehari-hari. Apabila kitab Wana Parwa disebarkan } \\
\text { maka akan dapat menuntun dan menbina masyarakat Hindu } \\
\text { kearah Spiritual yang tinggi. Kitab Wana Parwa mengandung } \\
\text { nilai-nilai pendidikan yang dapat dijadikan pedoman bagi siswa } \\
\text { Hindu seperti Nilai Kebajikan (Satyam), Nilai Kemandirian } \\
\text { (Swasisya), Nilai Usaha dan Kerja Keras (Tapa), Nilai Guru } \\
\text { Bhakti, Nilai Pengorbanan (Sevanam). Penelitian ini bertujuan } \\
\text { untuk menggali nilai-nilai pendidikan yang terkandung dalam } \\
\text { kitab Wana Parwa dan untuk mengetahui relevansi kitab Wana } \\
\text { Parwa dalam Pendidikan Agama Hindu agar dapat dijadikan } \\
\text { pedoman bagi siswa Hindu. }\end{array}$ \\
\hline $\begin{array}{l}\text { Keyword: } \\
\text { Wana Parwa, } \\
\text { Mahabratta, Hindu } \\
\text { Education Values }\end{array}$ & $\begin{array}{l}\text { Abstract } \\
\text { The Vedas are a source of basic teachings of Hinduism which are } \\
\text { used as guidelines and are applied in everyday life. Mahabratta is } \\
\text { included in the book Itihasa which is a start in studying the Vedic }\end{array}$ \\
\hline
\end{tabular}




\begin{tabular}{|l|l|}
\hline $\begin{array}{l}\text { scriptures. In the Parwa Mahabratta sections contained very noble } \\
\text { educational values that are taught and used as guidelines for Hindu } \\
\text { students. The Wana Parwa book is one part of the Mahabratta } \\
\text { book, in the Wana parwa book there are many educational values } \\
\text { that can be used as guidelines for Hindu students. The existence } \\
\text { of the Wana Parwa book among the Hindu community can be used } \\
\text { as a guide in everyday life, while the educational values contained } \\
\text { therein can be used as a guide in everyday life. If the book of Wana } \\
\text { Parwa is distributed it will be able to guide and foster Hindu } \\
\text { society towards a high Spiritual. The Wana Parwa book contains } \\
\text { educational values that can be used as guidelines for Hindu } \\
\text { students such as Virtue Value (Satyam), Independence Value } \\
\text { (Self-reliance), Business Value and Hard Work (Tapa), Values of } \\
\text { Bhakti Teachers, Value of Sacrifice (Sevanam). This study aims } \\
\text { to explore the educational values contained in the book of Wana } \\
\text { Parwa and to find out the relevance of the book of Wana Parwa in } \\
\text { Hindu Religious Education so that it can be used as a guide for } \\
\text { Hindu students. }\end{array}$ \\
\hline
\end{tabular}

\section{Pendahuluan}

Delapan Belas kitab Parwa dalam Mahabharata disebut dengan Asta Dasa Parwa. Wana Parwa adalah Parwa yang ke-3 setelah Sabha Parwa. Kedelapan belas Parwa tersebut menjadi sumber ajaran susastra suci Hindu. Ada beberapa dari Parwa sudah dibahasa Jawa Kunokan pada masa berkuasanya Raja Dharmawangsa Teguh Ananta Wikrama Tungga Dewa dengan nama Mangajawaken Byasa Mata, yakni membahasa jawa kunokan kitab karya dari Bhagawan Byasa.

Sebagaimana sumber tertulis, bahwa yang menulis kitab Mahabharata yang terdiri dari 18 Parwa adalah Bhagawan Byasa. Wana Parwa adalah kisah lanjutan dari Sabha Parwa, yakni setelah Panda kalah main dadu dan dibuang ke hutan. Jadi Wana Parwa adalah kisah pembuangan Pandawa di Hutan. Hal tersebut merujuk dari kata "Wana" dan "Parwa". Wana artinya hutan dan Parwa artinya kisah atau cerita. Jadi, Wana Parwa adalah kisah hutan yang mengisahkan pembuangan Pandawa di hutan.

Wana Parwa aslinya berupa bait mantra yang terdiri dari beratus-ratus sloka sanskerta. Tetapi telah banyak diterjemahkan dalam bentuk cerita, baik dari kalangan cendekiawan Hindu di Bali dan Barat. Dalam Wana Parwa kisahnya sangat berliku dan penuh dengan nilai-nilai yang dapat diterapkan dalam pembelajarn bagi siswa Hindu. Tidak saja itu, kisah Wana Parwa sesuai pula diterapkan oleh siwa Hindu didalam menghadapai tantangan zaman. Sebagaimana kisah Para Pandawa di hutan, demikianlah kehidupan kita sesungguhnya yang tidak luput dari 
ujian dan cobaan. Dengan mempedomani Nilai-nilai dalam Kitab Wana Parwa Siswa Hindu diharapakan mampu menjadi generasi yang cerdas, cakap, kreatif, memiliki mantalitas tinggi, dan berkarakter.

\section{Pembahasan}

\section{Isi Ringkas Kitab Wana Parwa}

Kitab Wanaparwa merupakan kitab yang mengisahkan kisah Pandawa selama masa 12 tahun pengasingan di dalam hutan belantara. Dalam kitab Wana Parwa dikisahkan Arjuna yang bertapa di gunung Himalaya untuk mendapatkan senjata sakti. Kisah Arjuna tersebut menjadi bahan cerita Arjunawiwaha. Secara ringkas isi kitab Wana Parwa disajikan sebagai berikut :

\section{Pandawa Memasuki Hutan Kamyaka}

Pandawa meninggalkan Gajahoya (Astinapura), rakyat mengikuti disarankan untuk kembali. Selanjutnya Pandawa meneruskan perjalanan sampai di bawah pohon beringin yang bernama "Pramana" di tepi sungai Gangga. Esok paginya Pandawa memulai masuk hutan dengan tetap diikuti oleh brahmana. Brahmana Sonaka menasehati, "Lebih baik jangan menyentuh lumpur sama sekali dari pada mencuci tangan yang kotor terkena lumpur." Bhagawan Domya yang menyertai perjalan tersebut menyarankan Yudhistira mohon anugrah dari Dewa Surya. Yudhistira melakukan hal tersebut sehingga mendapatkan anugrah belanga tembaga. Kegunaan belanga tersebut, yaitu akan berisi makanan saat diperlukan. Arya Widura menasehati raja Drestarastra agar memanggil Pandawa, tetapi sang raja justru mengusir Widura. Widura meninggalkan Hastina dan sampai pada Pandawa. Widura menasehati Pandawa, "Barang siapa yang tahan menanggung derita atas segala kesalahan yang dibuatnya akan menemukan kebahagiaan.

\section{Arjuna Bertapa}

Krishna dan Drestadyumena serta lainnya mengunjungi Pandawa. Dewi Subadra dan Abimayu dibawa oleh Betara Krishna ke Dwarawati. Putra-putra Drupadi dibawa oleh Drestadyumena ke Pancala. Pandawa melanjutkan perjalanan menuju ke sebuah danau suci dekat sungai Saraswati. Pandawa juga sempat didatangi oleh Rsi Markandeya, dan sang Rsi mansehati Pandawa untuk taat menjalani pembuangan. Pandawa juga dikunjungi oleh Brahmana Waka, dan menasehati Yudhistira agar menjadi Brahmana.

Drupadi merasakan penyesalannya yang mendalam. Drupadi berkata kepada Yudhistira, "Kita sudah berbuat kebajikan, tetapi kenapa kita mengalami nasib seperti ini?" Yudhistira 
menjawab, "Berbuat kebajikan merupakan kewajiban. Orang yang berbuat kebajikan dengan mengharapkan hasil itu pedagang kewajiban namanya. Kemudian Yudhistira melanjutkan lagi nasehatnya kepada Drupadi, "Seorang kesatria bukan saja harus mengalahkan musuh-musuhnya di luar diri, melainkan wajib pula menundukan musuhmusuh dalam diri."

Kemudian Bhagawan Byasa mengunjungi Pandawa, dan menyarankan Arjuna agar bertapa di gunung Himalaya. Lalu, Arjuna menuju gunung tersebut dan sesampainya di sana ia berjumpa dengan Hyang Indra. Hyang Indra mengajarkan Arjuna untuk dapat melihat Hyang Siwa. Sang Arjuna akhirnya melakukan tapa brata yoga Samadhi selama 6 bulan dan ada danawa bernama Muka datang dalam wujud babi. Arjuna memanah babi tersebut. Dalam waktu bersamaan ada pemburu bernama Kairata yang ikut memanah juga secara bersamaan. Mereka bersetegang, dan akhirnya pemburu Kairata berubah wujud menjadi Hyang Siwa. Hyang Siwa ternyata menjelma menjadi pemburu, dan menganugrahkan Arjuansenjata sakti Brahmastra Pasupata.(S. Pendit, Njoman : 138).

\section{Pandawa Melakukan Tirtha Yatra}

Ketika Arjuan bertapa, Rsi Narada mengunjungi Yudistira dan adik-adiknya. Atas pertanyaan Yudhistira, Rsi Narada menceritakan keutamaan Bertirtha Yatra. Atas nasehat tersebut, Pandawa malakukan Tirthayatra ke sungai suci Bhagirata. dalam perjalanannya Drupadi melihat bunga seroja yang dihembuskan angin. Drupadi kemudian menyruh Bima untuk mencari bunga tersebut. Bima mencari bunga tersebut di gunung Gandamandana. Dalam perjalanannya ke Gunung Gandamandana Sang Bima melihat Sang Hanoman. Mereka kemudian tentang Catur Yuga. Hanoman memberitahukan bahwa pada Zaman Kaliyuga kebajikan dharma tinggal seperempat, dan Sang Hanoman menunjukkan jalan dimana bunga seroja itu tumbuh. (S. Pendit Njoman, 168)

\section{Tahun Kesebelas}

Pada tahun kesebelas, Pandawa melanjutkan perjalanan menuju hulu sungai Yamuna. Dari sini mereka berjalan ke Danau Dwaitawana. Pada suatu hari Bima berjalan-jalan di hutan lalu ia dibelit ular besar. Sang ular mengisahkan dirinya bahwa ia adalah Raja Nashusha yang sudah mencapai Indraloka. Setelah lama Bima belum kembali, maka Yudhistira berusaha menemukan Bima yang sedang dililit ular besar. Akhirnya ular berhasil dilepaskan. Selanjutnya Pandawa melanjutkan perjalanannya dan memasuki hutan Kamyaka. Kemudian Betara Krishna mengunjungi Pandawa. Slenjutnya mereka dikunjungi Rsi Markandeya yang menceritakan kepada mereka tentang penciptaan alam semesta. 


\section{Kunjungan Para Kowara}

Pada suatu hari, seorang Brahmana mengunjungi Pandawa. Setelah mengunjungi Pandawa dan Brahmana lalu menghadap Raja Drestarastra menceritakan keadaan Pandawa yang memprihatinkan. Mendegar hal yang demikian para Korawa mengunjungi Pandawa dengan masksud memamerkan kemewahan. Sebelum memasuki hutan, para Kowara dicegat oleh pasukan Gandharwa dan tidak dijinkan untuk memasuki hutan. Para Korawa melarikan diri hingga tiba di tempat Pandawa. Lalu mereka memohon bantuan kepada Pandawa untuk mengalahkan Gandharwa. Ternyata Arjuna adalah bersahabat dengan pimpinan Gandharwa yakni Cetrasena. Arjuna kemudian menanyakan kepada Korwa dicegat. Citrasena menjawab, "Wahai Sahabtku Arjuna, mereka para Korawa memiliki niat jahat. Itulah sebabnya mengapa kami mencegat mereka." AKhirnya Arjuna meminta maaf dan Gandharwa membebaskan para Korawa. Duryodana merasa kecewa dan segera kembali ke Astinapura. Sesampianya di Astinapura, Bisma mengusulkan perdamaian dengan Pandawa. Pandawa agar dibebaskan dan segera dipulangkan dari pembuangannya. Duryodana menolak tegas, dan sangat murka atas usul tersebut.

\section{Drupadi diculik}

Pada suatu hari, pangeran Duryodana didatangi oleh Bhagwan Durwasa. Duryodana melayani Bhagawan Durwasa dengan segala kemewahan lalu ia mengusulkan agar Bhagawan Durwasan juga mengunjungi Pandawa. Begawan Durwasan beserta sertus muridnya mengunjungi Pandawa. Bhagawan dan para murid agar disediakan makanan, tetapi Yudhistira segera menyruh Bhagawan dan muridnya untuk mandi. Dewi Drupadi menjadi bingung, sebab persediaan beras dan nasi sudah tidak ada lagi. Kemudian ia memusatkan pikiran kepada Betara Krishna, dan seketika itu juga muncul dihadapan Drupadi dan memohon untuk disediakan makanan. Namun Drupadi mengatakan bahwa nasi sudah habis. Tetapi Betara Krishna meminta agar Drupadi menunjukkan periuk nasinya. Periuk tersebut ternyata berisi sebutir nasi. Betara Krishna pun segera memakan sebutir nasi tersebut sembari mengucapkan mantra. Kemudian para Rsi dan Bhagawan Durwasa sendiri kemudian tiba-tiba merasa kenyang dan tidak lapar lagi. Para Pandawa kemudian pergi berburu. Namun dalam perjalanannya berburu, Pandawa mendapatkan laporan bahwa Drupadi diculik oleh Jayadratha. Setelah rombongan dapat dikejar, maka Drupadi maka dapat dibebaskan, dan Jayadratha pun mealrikan diri.

\section{Tahun ke Dua Belas}


Setelah mengalahkan Raja Sindu dan menyelamatkan Drupadi para Pandawa pindah lagi dari hutan Kamyaka ke Dwaitawana. Pada suatu hari, tongkat kayu, alat penggosok api, dan penggaru susu kepunyaan seorang brahmana tersangkut pada tanduk kijang lalu dibawa lari oleh kijang tersebut. Sang brahmana lalu minta batuan kepada Pandawa untuk mendapatkan kembali barang-barang yang didirikan oleh si kijang. (S.Pendit : 181). Para Pandawa secara bersama-sama mengejar kijang tersebut namun sampai kelelahan kijang yang dikejar menghilang tanpa meninggalkan jejak. Mereka lalu beristirahat di bawah pohon beringin. Yudhistira minta agar Nakula pergi mencari airnya yang jernih. Segera Nakula bermaksud minum, dan dari angkasa munculan sabda "Hai, nak telaga ini milikku. Jika engkau ingin minum kau harus minta izin dalu padaku. Aku akan mengizinkan apabila engkau bisa menjawab segala pertanyaanku." Karena sangat haus Nakul tidak menghiraukan sabda tersebut, dan langsung meminum air tersebut. Selesai minum air tersebut, Nakula rebah tidak bernyawa. (S.Pendit :183). Sudah sekian lama Nakula tidak kembali, maka ia menyuruh Sahadewa untuk menyusul. Sahdewa pun tidak kembali dan mengalami nasib yang sama rebah tidak bernyawa. Semua adik-adiknya Yudhistira pun rebah dalam dipinggir sumber air tersebut. Setelah keempat adiknya tidak datang, Yudhistira merasa gundah dan segera menyusul. Alangkah terkejutnya setelah mendapati keempat adiknya rebah tidak bernyawa. Pada saat itulah, terdengar suara dari atas. Suara tersebut datangnya dari Yaksa, dan Yaksa bertanya, "Aku adalah Yaksa penguasa telaga ini. Karena saudaramu telah meminum air ini tanpa ijin. Aku akan memberikanmu minum air ini jika kamu dapat menjawab segala pertanyaannku. "Selanjutnya Yusdhistira bersedia menjawab segala pertanyaan dari Yaksa. Pertanyaan tersebut semua dijawab dengan baik dan benar. Yaksa merasa puas dan segera menghidupkan kembali saudara-saudara Pandawa. Selain itu, Yudhistira begitu sangat teguh dalam dharma.(S.Pendit, Njoman: 189)

\section{Nilai - Nilai Pendidikan dalam Kitab Wana Parwa}

\section{Nilai Kebajikan (Satyam)}

Kebajikan adalah sikap yang terpuji. Sikap tersebut dimiliki oleh Pandawa ketika menjalani masa pembuangan ke hutan. Kebajikan yang diperlihatkan Pandawa menyebabkan Pandawa sering dikunjungi orang suci, meskipun tinggal di hutan. Kebajikan Pandawa tersebut dapat terlihat dari keteladanan Yudhistira sebagai kakak 
tertua dari Pandawa. Drupadi mungkin merasa sedih sebab ia harus tinggal di dalam hutan. Tetapi, Yudhistira sangat taat dan tabah untuk menjalani masa pembuangan tersebut. Yudhistira bahkan mengatakan kepada Drupadi, bahwa kebajikan adalah "kewajiban" yang harus dijalankan manusia. Berbuat kebajikan tetapi mengharapkan akan hasil, maka hal tersebut sama dengan menjual kebajikan. Perbuatan yang demikian sungguh tidak terpuji dan bertentangan dengan ajaran dharma. Atas hal itu, Yudhistira begitu sangat taat menjalankan masa pembuangannya. Penderitaan pada masa pembuangan justru mengajarkan mereka untuk dapat berbuat kebajikan kepada semua makhluk.

Bahkan kepada musuh sekalipun Pandawa menjalankan kebajikan. Hal tersebut terlihat ketika Korawa diserang Gandharwa. Arjuna ketika itu menolong para Korawa atas perintah Yudhistira. Hal tersebut menunjukkan kebajikan Yudhistira yang tidak memandang kawan maupun lawan. Sebab kebajikan adalah kewajiban. Kita sebagai siswa Hindu juga hendaknya dapat mengembangkan kebajikan dalam diri sebagai sebuah kawajiban.

Nilai kebenaran (satya) dapat ditemukan dalam Bhagawad Gita 16.2 sebagai berikut :

$$
\begin{aligned}
& \text { ahiḿsā satyam akrodhas } \\
& \text { tyāgaḥ śāntir apaiśunam } \\
& \text { dayā bhūteșv aloluptvaḿ } \\
& \text { mārdavamón hrīr acāpalam }
\end{aligned}
$$

(Bhagwad Gita, XVI.2)

Artinya, 'tanpa kekerasan, kebenaran, tidak kemarahan, renunsiasi, ketenangan/kedamaian, tidak memfitnah, welas asih kepada semua makhluk, tidak tamak, kelembutan, kerendahan hati, tidak berubah-ubah' adalah sifat-sifat dari mereka yang lahir dari kesucian'. (SwamiParbhupada, 733)

\section{Nilai Kemandirian (Swasisya)}

Selain nilai kebajikan, nilai kemandirian sangat jelas nampak diperlihatkan oleh Pandawa dalam kisah Wana Parwa. Sikap mandiri merupakan sikap yang patut ditumbuhkembangkan dalam diri sebagai siswa atau peserta didik. Kemandirian akan mengajarkan siswa untuk dapat bertanggung jawab menjadi siswa. Selayaknya ketika Pandawa mengalami masa pengasingan di hutan. Selama masa itu, Pandawa bertanggung jawab terhadap istrinya Drupadi dan ibunya sendiri Dewi Kunti. Sebagaimana nasehat Sang Widura kepada Pandawa agar Pandawa menanggung derita yang dibuatnya sendiri maka akan menemukan kebahagiaan kelak.

Mengalami masa pembuangan di hutan bukanlah masa yang indah, tetapi masa sulit. Bayangkan mereka tinggal dihutan dan sangat jauh dari kemewahan. Hidup sangat 
sederhana, tetapi Pandawa melakukannnya dengan taat dan melakukan segala pekerjaan untuk mereka hidup. Jadi Pandawa tidak bergantung pada orang lain untuk mereka dapat hidup.

Sikap yang dimiliki tokoh Pandawa tersebut sesungguhnya dapat dijadikan gambaran sebagai motivasi agar kita sebagai siswa Hindu memiliki sikap mandiri. Sebagai siswa Hindu, kemandirian merupakan salah satu cara untuk memupuk rasa tanggung jawab, Mandiri dalam mengerjakan soal ulangan, tugas, dan segala pekerjaan yang dibebankan oleh guru maupun orang tua di rumah.

\section{Nilai Usaha dan Kerja Keras (Tapa)}

Tapa memiliki arti yang sangat luas, dan dalam hal ini tapa diartikan sebagai usaha dan kerja keras. Sikap tapa tersebut sangat jelas dikisahkan dalam kisah Wana Parwa. Pandawa menjalani pembuangan di hutan dan dapat melewati dengan baik disebabkan karena usaha dan kerja keras. Keberhasilan pandawa melewati 13 tahun pembuangan dihutan adalah melalui usaha dan kerja keras.

Selain itu, tapa juga diperlihatkan oleh Sang Arjuna ketika bertapa untuk mendapatkan senjata Brahmastra Pasupati. Senjata tersebut didapat Arjuna melalui tapa yang hebat selama 6 bulan. Demikian pula siswa Hindu hendaknya menjalankan prinsp berusaha dan bekerja keras maka kesuksesan akan didapat. Se gala sesuatu membutuhkan pengorbanan. Tidak ada sesuatu yang didapat secara cuma-cuma tanpa berusaha dan bekerja keras. Demikian pula, ilmu pengetahuan yang didapat harus berdasarkan atas usaha dan kerja keras. Tidak mungkin ilmu pengetahuan didapat dengan cara yang mudah. Berdasarkan atas hal tersebut, siswa dalam ajaran agama Hindu disebut dengan Siksa atau sisya yang berarti hidup dalam usaha dan kerja keras.

Berkerja yang dimaksud tidak hanya sebagai karyawan atau pegawai tapi juga pekerjaan yang tidak mendapat upah atau imbalan sekalipun, seperti gotong royong, membantu sesama, gerakan menjaga lingkungan. Meskipun dalam pekerjaan itu tidak mendapatkan upah kita harus bekerja dengan serius dan penuh semangat, saat bekerja kita tidak perlu memikirkan hasil yang akan kita peroleh dalam pekerjaan itu tapi, lakukan yang terbaik dalam pekerjaan itu tanpa memikirkan hasilnya. Seperti isi sloka yang terdapat dalam kitab Bhagawad Gita Bab II Sloka 47 sebagai berikut :

$$
\begin{gathered}
\text { Karmany evadhikaras te } \\
\text { Ma phalesu kadacana } \\
\text { Ma karma phala heturbhur } \\
\text { Ma te sanggostava akarmani }
\end{gathered}
$$


Artinya :

Hanya berbuat untuk kewajiban bukan hasil perbuatan itu (kau pikirkan), jangan sekalikali pahala yang menjadi motifmu bekerja, jangan pula tidak bekerja (sebab tak berharap pahala).

(Swami Prabhupada, 133)

Dalam paham kerja ini, hanya semata-mata untuk pahala material (pamrih), atau sama sekali tidak bekerja, (nirkarma) karena semata-mata sesempit "angin di kurungan ruas bambu" sindiran Mpu Kanwa. Dalam Singhalayang Parwa, dinyatakan : "tan hanang wastu tan palalayan" (tiada anugerah tanpa suatu usaha sungguh-sungguh untuk menggapainya Dengan demikian, tapa dan jnana atau usaha dan ilmu hendaknya berjalan beriringan. Dalam arti, siswa yang ingin berilmu maka harus melalui sebuah usaha yang keras. Tidak mungkin untuk mendapatkan pengetahuan seseorang hanya hidup dalam bermalasmalasan. Pasti melalui usaha dan kerja keras. Siswa belajar adalah sebuah proses di dalamnya ada usaha. Ibarat naik pada tangga, pasti diawali dengan menaiki tangga paling bawah secara bertahap seterusnya. Artinya, belajar adalah sebuah proses dimulai darin bawah, dan untuk menuju tangga puncak memerlukan usaha dan kerja keras.

\section{Nilai Guru Bhakti}

Nilai berikutnya yang terdapat dalam kisah Wana Parwa adalah nilai Guru Bhakti. Dalam pembelajaran pasti melibatkan antara guru dengan murid. Ketika murid berkeinginan untuk mendapatkan pengetahuan dari guru, maka murid harus berbakti kepada guru. Bakti seorang murid kepada guru digambarkan dengan sangat jelas dalam Wana Parwa. Misalnya, ketika Rsi Markendya datang menemui Pandawa. Beliau sang Rsi menyampaikan kepada Arjuna untuk bertapa di Gunung Indrakila. Perintah Rsi Markendya sebagai guru Pandawa dijalankan dengan bakti oleh Arjuna.

Tidak ada sedikitpun Sang Arjuna menolak perintah dari guru. Sebab Arjuna sangat menghormati gurunya. Sang Arjuna yang hormat pada guru, maka ia mendapatkan segala pengetahuan dari gurunya. Menjalankan perintah guru adalah etika seorang murid. Siapapun dari siswa yang dapat menghormati guru, maka ia dapat dipandang sebagai yang memiliki pengetahuan. Ia akan menjadi orang yang cerdas dan berpengatahuan. Sebaliknya siapa yang berani kepada guru, maka ia akan menjadi orang bodoh (avidya). Sebagaimana ditunjukkan oleh Korawa yang tidak menghormati dan bakti kepada para guru rsi. Korawa 
justru mencaci mereka dengan kata-kata kasar, sehingga mereka pada kahirnya menemukan penderitaan dan kehancuran. Selamanya Korawa berada dalam kebodohan dan kegelapan pikiran. Sebab dalam kasanah pengetahuan Hindu, pengetahuan adalah pelita dan penerang manusia dari kegelapan.

Dalam kehidupan ini peran dan fungsi guru sangat pent-ing. Tanpa adanya guru, maka manusia masih terbelenggu dalam kehidupan yang diselimuti kegelapan (avidya). Disinilah guru memiliki peran dan fungsi strategis untuk me-lepaskan manusia dari keadaan yang paling menyengsarakan, yaitu kebodohan menuju pada kehidupan yang berpengetahuan (vidya). Dalam perkembangannya, ternyata peran dan fungsi guru dalam kehidupan sudah mulai terabaikan. Artinya rasa hormat, terima kasih dan upaya untuk menghargai jasa-jasa guru sudah semakin berkurang. Bahkan tindakan yang tidak terpuji kepada guru semakin meningkat. Seperti kasus pemukulan terhadap guru, penghinaan dan pelecehan. Bila hal ini terus terjadi, maka inilah pertanda bahwa degradasi moral dalam kehidupan ini semakin meningkat.

Siswa yang baik adalah siswa yang selalu memiliki sikap hormat kepada guru. Tidak saja kepada guru, kepada sesama dan lingkungan juga kita harus memiliki rasa hormat kepada mereka. Sebab tanpa adanya semua itu kita tidak dapat hidup di alam ini. Prinsip Guru-Bhakti tersebut tidak saja dilakukan di sekolah. Berbakti kepada guru bisa dilakukan pula di rumah, yakni hormat kepada orang tua. Sebagaimana Pandawa yang selalu menghormati para orang suci yang dijadikan guru. Kisah yang menarik adalah Pandawa selalu melakukan apapun suruhan dari guru mereka. Bhagawan Byasa menyuruh Pandawa tirtha yatra, dan mereka mengikuti perintah guru. Dalam Kitab Sarasamuccaya disebutkan sebagai berikut :

Nyang daya, haywa juga ngwangnsumahur awahil-wahilan lawan guru, mangkana yar abuteng, anumanan sira, asih-asihen, patenikang sanukana ri manah nira.

(Sarasamuccaya : 237)

Artinya

Bahwa yang patut dilaksanakan terhadap guru adalah sebagai berikut: jangan menjawab secara berolok-olok kepada guru, jika beliau gusar, berang hatinya, sabarkan beliau, hiburlah usahakanlah segala yang menyenangkan beliau. (Kajeng, 1997: 181)

Prinsip Guru-Bhakti tersebut dapat diwujudkan dalam perilaku, seperti tidak melawan perintah orang tua, patuh kepada orang tua dan hidup dalam kedisiplinan. Jadi, mengikuti perintah orang tua dan tidak mewalannya adalah sikap terpuji dan siswa yang tidak melawan orang tua maka dirinya akan menjadi orang yang berpengetahuan. Orang tua akan 
menjadi senang dan gembira, sehingga orang tua akan mendoakan untuk siswa mendapatkan kesuksesan.

Apabila seseorang dalam hidupnya tidak menerapkan ajaran Guru Bhakti, maka hidupnya diliputi dengan penderitaan, kesengsaraan, kesedihan dan selalu dirundung dengan musibah serta malapetaka. Maka dari itu untuk mewujudkan kebahagiaan dalam hidup, hal yang mesti dilakukan adalah berbhakti kepada para guru. Manusia yang selalu menanamkan rasa bhakti kepada para guru adalah mereka yang selalu terberkati, terlindungi dan mendapatkan anugerah yang luar biasa. Guru sesungguhnya pelepas kegelapan dalam hidup yang mampu menuntun ke arah cahaya kehidupan yang bahagia. Karena ajaran guru bhakti merupakan penuntun untuk mampu meraih dan mewujudkan kebahagiaan yang utama. (Sudipta I Nyoman, 2016)

\section{Nilai Pengorbanan (Sevanam)}

Nilai berikutnya yang terkandung dalam kisah Wana Parwa adalah berkenaan dengan pengorbanan. Pengorbanan adalah sikap yang dimuliakan dalam ajaran agama Hindu. Berkorban bukan berarti bertindak semena-mena terhadap orang lain, tetapi menjadikan segala bentuk karma atau perbuatan sebagai pengorbanan.

Pengorbanan yang paling utama adalah Drupadi sebagai seorang istri begitu dengan setia mengorbankan dirinya untuk ikut serta dalam masa pembuangan yang dilakukan oleh Pandawa. Sikap rela berkoban yang dilakukan Drupadi merupakan cerminan dari perilaku yang baik. Selain Drupadi, Pandawa juga rela berkorban demi janji mereka untuk menjalankan kehidupan di hutan. Meninggalkan segala kemewahan istana dan hidup sederhana di hutan. Semua yang mereka lakukan adalah salah satu bentuk pengorbanan yang sangat tulus dan iklas.

Sikap rela berkoban tersebut ditunjukan pula oleh Sang Bima. Sang Bima adalah salah satu dari lima Pandawa yang paling kuat. Ia memiliki kekuatan sepuluh gajah, dan pengorbanannya terhadap adik-adik dan saudaranya di Pandawa sangat banyak. Dalam kisah Wana Parwa dikisahkan adalah perngorbanannya untuk mencari bunga seroja di gunung Gandanamandana. Pengorbanannya ia harus dibelit ular dan hingga akhirnya bertemu dengan Sang Hanoman. Sebelum ia menemukan bunga seroja tersebut, Sang Bima justru mendapatkan berbagai macam pengetahuan dari Sang Hanoman. Artinya, nilai yang dapat kita ambil, bahwa pengorbanan adalah sangat penting untuk kita mendapatkan pengetahuan/ilmu. 
Sebagai siswa, sikap rela berkorban hendaknya selalu dimunculkan dan ditumbuhkembangkan dalam diri. Sikap rela berkorban pun hendaknya dilakukan dengan tulus dan iklas. Contoh sikap rela berkorban adalah melakukan perbuatan berderma (dana punia), menyumbang, memberisihkan lingkungan sekolah, sikap suka menolong, mebantu orang tua dan perbuatan baik lainnya. Semua perilaku tersebut menunjukkan sikap yang rela berkorban. Jika, kemudian siswa dapat berperilaku demikian maka ia akan mendapatkan ilmu pengetahuan dari guru. Nilai rela berkorban dapat ditemukan dalam Bhagawad Gita 18.43 seperti dalam petikan sloka berikut:

$$
\begin{gathered}
\text { śauryaḿ tejo dhṛtir dākșyaḿ } \\
\text { yuddhe cāpy apalāyanam } \\
\text { dānam īśvara-bhāvaś ca } \\
\text { kṣātraḿ karma svabhāva-jam }
\end{gathered}
$$

(Bhagawad Gita : XVIII.43)

Artinya :

Kepahlawanan, kekuatan, tekad, kecerdikan, keberanian dalam pertempuran, kemurahan hati dan kepemimpinan adalah kualitas alami dari pekerjaan untuk para Ksatriya.

( Swami Prabhupada : 820)

Arjuna adalah orang yang rela mengabdikan hidupnya untuk kebenaran suci dan kebenaran batin serta berbagi visinya dengan seluruh dunia. Pahlawan adalah orang yang membentang melintasi zaman, ia berbicara kepada generasi di luar dirinya sendiri. Pahlawan adalah wujud kedewasaan, juga perwujudan dari laki-laki utama.

Sikap rela berkorban juga penting dilakukan kepada Bangsa dan Negara kita Indonesia. Sikap rela berkorban bagi siwa Hindu dapat dilakukan dengan mengisi kemerdekaan ini dengan segala bentuk prestasi. Belajar dengan giat, tekun dan rajin bersekolah merupakan bentuk dari sikap rela berkorban.

Pengorbanan berikutnya adalah sikap toleransi. Pandawa menunjukkan sikap tersebut dengan mebantu Korawa, yakni musuhnya sendiri. Korawa berbuat tidak baik pada Pandawa. Maka mereka dihadang oleh Gandharwa. Korawa melarikan diri meminta tolong kepada Pandawa. Yudhistira menyuruh Arjuna melawan Gandharwa. Ternyata Gandharwa adalah sahabatnya Arjuna. Pada akhirnya Korawa dilepaskan, hal tersebut menunjukkan sikap rela berkorban. Rela mengorbankan dirinya untuk menyeamatkan Korawa musuhnya sendiri. 


\section{Simpulan}

Kitab Wana Parwa mengandung Nilai-nilai Pendidikan yang sangat luhur. Nilai-nilai tersebut sangat baik dijadikan pedoman sebagai umat Hindu dalam menjalani kehidupan di dunia ini. Nilai-nilai Pendidikan yang terkandung dalam Kitab Wana Parwa antara lain : Nilai Kebajikan (satyam), Nilai Kemandirian, Nilai Usaha dan Kerja Keras (Tapa), Nilai Guru Bhakti, Nilai Pengorbanan (Sevanam) Kebajikan adalah sikap yang terpuji. Sikap tersebut dimiliki oleh Pandawa ketika menjalani masa pembuangan ke hutan. Sikap mandiri merupakan sikap yang patut ditumbuhkembangkan dalam diri sebagai siswa atau peserta didik. Kemandirian akan mengajarkan siswa untuk dapat bertanggung jawab menjadi siswa. Tapa memiliki arti yang sangat luas, dan dalam hal ini tapa diartikan sebagai usaha dan kerja keras. Sikap tapa ditunjukan oleh Pandawa saat menjalani hukuman di tengah hutan selama masa pembuangannya. Prinsip Guru-Bhakti dapat diwujudkan dalam perilaku, seperti tidak melawan perintah orang tua, patuh kepada orang tua dan hidup dalam kedisiplinan. Pengorbanan adalah sikap yang dimuliakan dalam ajaran agama Hindu. Berkorban bukan berarti bertindak semenamena terhadap orang lain, tetapi menjadikan segala bentuk karma atau perbuatan sebagai pengorbanan.

\section{Daftar Pustaka}

Adnyana, I Gede Agus Budhi, Sandika I Ketut. 2010. Bhisma Parwa dan Nilai Pendidikan Bagi Siswa Hindu. Gianyar: PT Gandapura.

Donder, I Ketut. 2004. Sisya Sista Pedoman Menjadi Siswa Mulia Dalam Perspektif Relegiososiolenguistik Edukatif. Denpasar : Pustaka Bali Post

Kadjeng, I Nyoman DKK, Sarasamuccaya, 1999. Surabaya : Paramita Surabaya

Mantra. IB. 2016. Tata Susila Hindu. Denpasar: Udayana University Press.

Narayana, Sri Satya Swami. 1999. Pendidikan Nilai-Nilai Kemanusiaan Dalam Wejangan Bhagawan Sri Satya Sai Baba. Jakarta: Sai Books Trust.

Nurkancana. I Wayan.2010. Keutamaan Mahabharata. Denpasar: Pustaka Manik Geni.

S Pendit, Njoman. Mahabharata. Djkarta: P.N Pertjetakan Negara R.I

Subramaniam, Kamala. Mahabharata. 2003. Suarabaya : Paramita Surabahya

Nala, I Gusti Ngurah. 2004. Murdha Agama Hindu. Denpasar : Upada Sastra

Sura, I Gede. 2001. Pengendalian Diri dan Etika Dalam Ajaran Agama Hindu. Denpasar : Hanuman Sakti 
Sri Srimad A.C Bhaktivedanta Swami Prabhupada : Bhagwad Gita Menurut Aslinya : Hanuman Sakti

https://id.wikipedia.org/wiki/Jayadrata diunduh 29Agustus 2019 Pk1.2100 